\title{
Investigating Multiphase Flow Phenomena in Fine-Grained Reservoir Rocks: Insights from Using Ethane Permeability Measurements over a Range of Pore Pressures
}

\author{
Eric Aidan Letham $(\mathbb{D}$ ) and Robert Marc Bustin \\ Department of Earth, Ocean and Atmospheric Sciences, The University of British Columbia, 2020-2207 Main Mall, \\ Vancouver, BC, Canada V6T $1 Z 4$ \\ Correspondence should be addressed to Eric Aidan Letham; ealetham@gmail.com
}

Received 19 September 2017; Revised 13 December 2017; Accepted 3 January 2018; Published 7 March 2018

Academic Editor: Tongqiang Xia

Copyright (c) 2018 Eric Aidan Letham and Robert Marc Bustin. This is an open access article distributed under the Creative Commons Attribution License, which permits unrestricted use, distribution, and reproduction in any medium, provided the original work is properly cited.

\begin{abstract}
The ability to quantify effective permeability at the various fluid saturations and stress states experienced during production from shale oil and shale gas reservoirs is required for efficient exploitation of the resources, but to date experimental challenges prevent measurement of the effective permeability of these materials over a range of fluid saturations. To work towards overcoming these challenges, we measured effective permeability of a suite of gas shales to gaseous ethane over a range of pore pressures up to the saturated vapour pressure. Liquid/semiliquid ethane saturation increases due to adsorption and capillary condensation with increasing pore pressure resulting in decreasing effective permeability to ethane gas. By how much effective permeability to ethane gas decreases with adsorption and capillary condensation depends on the pore size distribution of each sample and the stress state that effective permeability is measured at. Effective permeability decreases more at higher stress states because the pores are smaller at higher stress states. The largest effective permeability drops occur in samples with dominant pore sizes in the mesopore range. These pores are completely blocked due to capillary condensation at pore pressures near the saturated vapour pressure of ethane. Blockage of these pores cuts off the main fluid flow pathways in the rock, thereby drastically decreasing effective permeability to ethane gas.
\end{abstract}

\section{Introduction}

Effective matrix permeability is one control on the deliverability of hydrocarbons, and therefore the economics of shale oil and shale gas wells [1]. Being able to quantify effective permeability at initial reservoir saturation and the range of saturations experienced during production from these reservoirs is thus paramount to efficient exploitation of the resource. Hydrocarbons in shale oil and shale gas reservoirs travel in the presence of multiple immiscible fluids through small pores in the fine-grained matrix prior to reaching a fracture network leading to the wellbore. Immiscible phases include one or both of liquid and gaseous hydrocarbons as well as connate water and imbibed hydraulic fracturing fluid. Capillary pressures across the interfaces of these immiscible phases can be enormous due to how small the pores are in shales (nanometer to micrometer length scale (e.g., [2])). The small pore length scale also means that geometrical constrictions imposed by fluid adsorbed to pore walls can significantly inhibit flow [3]. Effective permeability of hydrocarbon phases will therefore be very sensitive to the presence and saturation of the different fluid phases $[3,4]$.

To date, researchers have had minimal success investigating multiphase flow characteristics of shale due to challenges associated with characterizing reservoir rocks with small length scale pore systems. These challenges include the difficulty in controlling and monitoring fluid saturations and distributions in intact samples, and, because of their inherently low permeability, difficulty in quantifying the very low flow rates characteristic of shales. Combined, these challenges have prevented measurement of effective permeability over a range of fluid saturations and thus impaired our understanding of shale multiphase flow phenomena.

In this study, we investigate multiphase flow phenomena in fine-grained rocks by measuring effective permeability of a suite of shale samples to gaseous ethane over a range of 


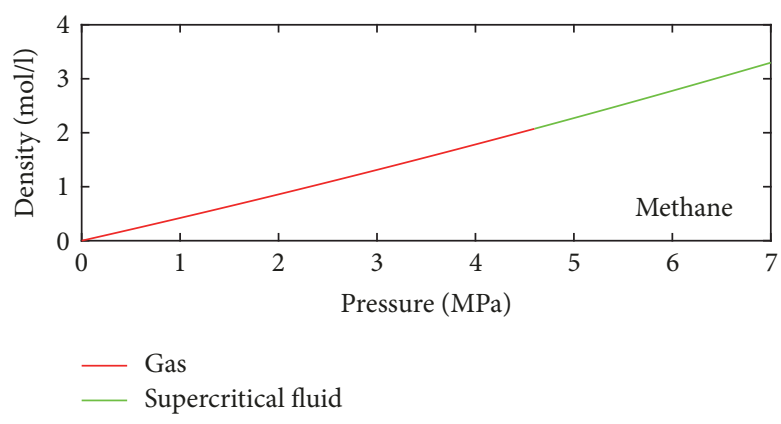

(a)

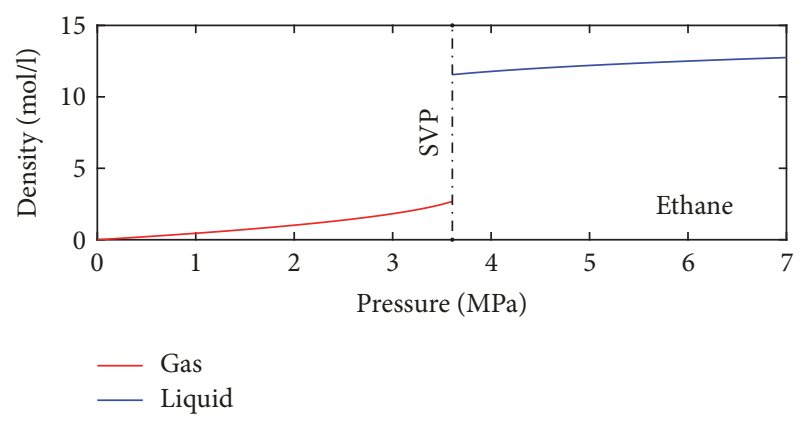

(b)

FIGURE 1: Isothermal density-pressure relationships for methane (a) and ethane (b) at laboratory temperature ( $\left.18^{\circ} \mathrm{C}\right) . \mathrm{SVP}$ is saturated vapour pressure. Data from Lemmon et al., 2017.

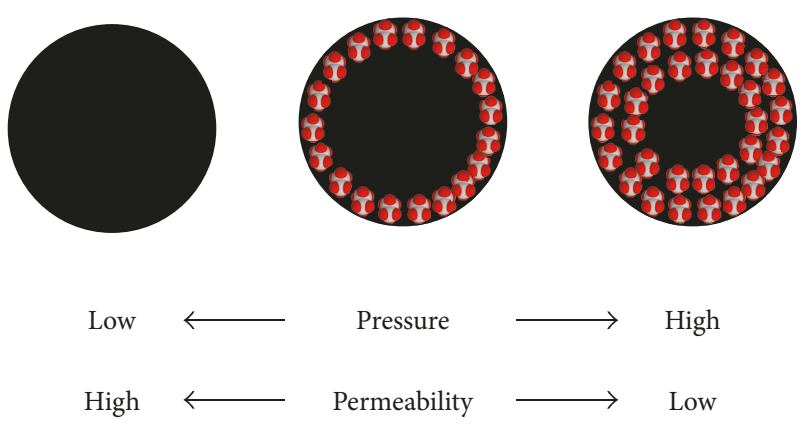

FIGURE 2: Schematic cross sections of pore throats showing adsorbed liquid/semiliquid ethane (red and grey molecules) restricting flow paths for ethane gas at high gas pressure, resulting in decreased effective permeability to ethane gas.

pore pressures up to the saturated vapour pressure (3.59 MPa at $\left.18^{\circ} \mathrm{C}\right)$. At laboratory temperature, pure ethane can exist as a liquid or a gas, depending on pressure (Figure 1(b)). In contrast, methane, the dominant component of natural gas, is either a gas or a supercritical fluid (Figure 1(a)). At the range of pressures found in natural gas reservoirs, methane typically adsorbs to the pore walls of organic rich rocks to form a monolayer, resulting in Type I (Langmuir) isotherms [5]. In contrast, multilayer adsorption is expected for ethane at pore pressures approaching the saturated vapour pressure, which is why we chose ethane as a probing gas for this study; a wider range of adsorbed liquid/semiliquid fluid saturations can be achieved using ethane compared to that if methane is used as a probing gas.

Saturation of liquid/semiliquid ethane increases with increasing pore pressure due to adsorption and capillary condensation, resulting in decreased permeability to ethane gas (Figure 2). These permeability decreases vary across a suite of samples with varying pore size. By measuring pore size of the sample suite using gas slippage measurements, we show that the largest drops in ethane relative permeability take place in rocks with the smallest pores. We show that gas slippage measurements can be used to predict relative permeability and therefore aid in predicting the deliverability of hydrocarbons from a shale oil or shale gas reservoir.

\section{Methods}

2.1. Sample Suite. The sample suite includes two gas shales from the Eagle Ford Formation in Texas, USA (TEFB9 and TEF21), and three gas shales from the Montney Formation in British Columbia, Canada (MONT, B5FD1B6, and B5FD2A2). The Eagle Ford and Montney formations are two very important hydrocarbon producers $[7,8]$. The sample suite was chosen so that a wide range of matrix permeabilities and pore sizes were investigated. Sample TEFB9 was subsampled for two $3 \mathrm{~cm}$ diameter by $\sim 3 \mathrm{~cm}$ length plugs, one oriented for fluid flow parallel to bedding (TEFB9Pll) and one for fluid flow perpendicular to bedding (TEFB9Pd). Subsample TEFB9Pll was evaluated at multiple stress states to understand the impact of the shale's stress sensitive pore structure on its multiphase flow characteristics. For the rest of the samples, a single plug oriented for fluid flow parallel to bedding was evaluated at one stress state to build up a data set large enough that the multiphase flow characteristics of different shales could be compared.

2.2. Permeability Measurements. Permeability measurements to helium and ethane were made on each sample using the pulse decay technique [9] at laboratory temperature (18 degrees Celsius). Helium, an inert gas that does not adsorb to pore walls, was used for petrophysical characterization of pore structures in the absence of adsorbed fluid. Measurements were made at a range of different pore pressures (Figure 3) to vary mean free path of the gas such that Klinkenberg plots could be generated (apparent permeability, $K_{a}$, against inverse pore pressure). The difference between pore pressure $\left(P_{p}\right)$ and confining pressure $\left(P_{c}\right)$, referred to herein as "simple effective stress," was kept constant by changing confining pressure by the same amount as pore pressure. Linear fits of the Klinkenberg plot data were extrapolated to infinite pore pressure in order to determine slip-free permeability, $K_{\infty}$, and Klinkenberg's slippage factor, $b[10]$

$$
K_{a}=K_{\infty}\left(1+\frac{b}{P_{p}}\right) .
$$




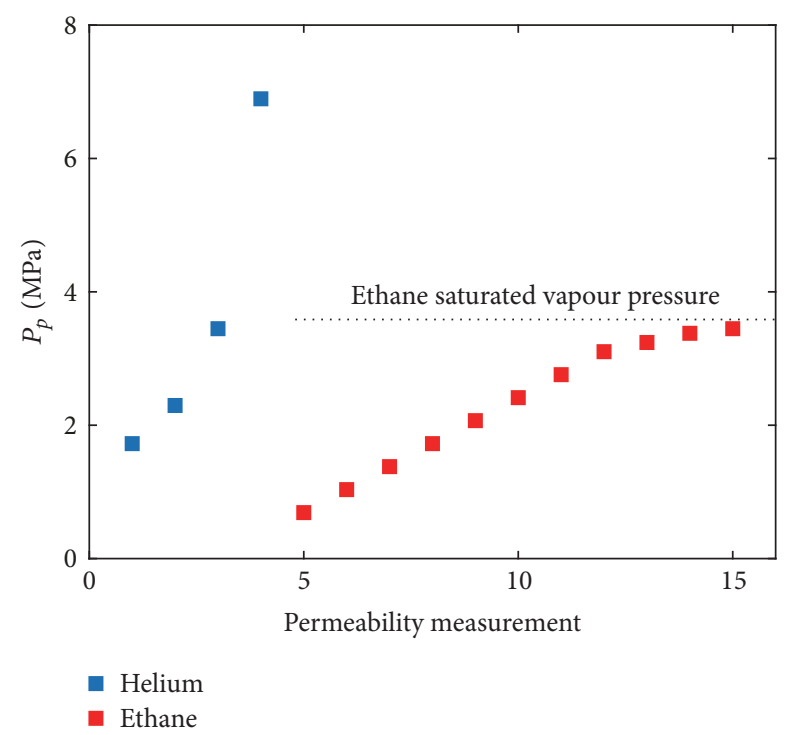

FIgUre 3: Pore pressure schedule for the suite of helium (blue) and ethane (red) permeability measurements made on each sample. The ethane saturated vapour pressure at the temperature of the permeability measurements $\left(18^{\circ} \mathrm{C}\right)$ is $3.59 \mathrm{MPa}$.

Determining $b$ allows calculation of dominant pore size, $d$ [10], which represents an average diameter of the smallest pore throats along those flow paths responsible for the bulk of the fluid flux through the rock, calculated using a simplified model that represents pores as cylindrical capillary tubes [11]

$$
d=\frac{8 c \lambda P_{p}}{b}
$$

where $c$ is Adzumi's constant (0.9 [12]), $P_{p}$ is pore pressure, and $\lambda$ is mean free path

$$
\lambda=\frac{R T}{\sqrt{2} \pi d_{\text {kin }}^{2} N_{A} P},
$$

where $R$ is the gas constant, $T$ is temperature, $d_{\text {kin }}$ is kinetic diameter, $N_{A}$ is Avogadro's constant, and $P$ is pressure [13].

Pore size estimates from gas slippage measurements could also be made assuming pores have slot-shaped cross-sectional geometries [14]. Although some studies argue based on photomicrographs that pores of some gas shales are more slot shaped than circular in cross section (e.g., [15]), recent analysis of a large compiled data set that includes many different gas shales suggests that pores in fine-grained sedimentary rocks are more accurately modelled as circular in crosssectional geometry [11]. We therefore use the circular model (see (2)) to estimate pore size from gas slippage measurements in this study.

Ethane permeability measurements were made at a range of mean pore pressures increasing from 0.69 to $3.45 \mathrm{MPa}$ (Figure 3). Pressure was allowed to equilibrate for a minimum of 12 hours at each pressure step. Pressure was monitored during the equilibration period and sufficient time was allowed for pressure to stabilize prior to measurement. Pressure pulses of $0.24 \mathrm{MPa}$ were generated by bleeding off pressure from the downstream reservoir. Pressure pulses need to be small enough that flow is laminar. While early studies of the pulse decay technique suggest a maximum pressure gradient of $0.03 \mathrm{MPa} / \mathrm{cm}$ [16], much smaller than the gradients imparted in the present study $(0.08 \mathrm{MPa} / \mathrm{cm})$, recent work shows that pressure gradients much greater than $0.03 \mathrm{MPa} / \mathrm{cm}$ can be used and flow still be in the laminar flow regime in low permeability samples [17]. Differential pressure was allowed to decay until reaching $0.01 \mathrm{MPa}$ or, for lower permeability samples where differential pressure decays very slowly, until enough data was collected for an accurate permeability measurement.

2.3. Permeability Calculation. Permeability was calculated from the pulse decay data using the equations presented in Cui et al. [18]. An isothermal pressure-viscosity curve [19] was used to determine the correct ethane viscosity for each permeability calculation. Adsorption/desorption was not accounted for in any of the permeability calculations. Ethane is a strongly sorptive gas and therefore adsorption/desorption could impact the accuracy of calculated ethane permeabilities [18]. However, the upstream and downstream reservoirs of the permeameters used in this study are much larger than pore volumes of the samples ( 10 times), so error in our permeability measurements resulting from not accounting for adsorption/desorption is less than 10\% [18].

Feng et al. $[17,20]$ presented an experimental setup that would eliminate the need to account for adsorption when calculating permeability from pulse decay data. In their setup, the pressure pulse is generated by both increasing the upstream gas pressure and decreasing the downstream gas pressure by equal amounts from equal volume reservoirs. Pressure would therefore come to equilibrium at the same pressure the sample was soaked at prior to measurement, and the quantity of ethane adsorbed would be the same before and after the pressure decay. We did not adopt the experimental setup of Feng et al. $[17,20]$ because, in addition to quantifying permeability at each pressure step, we wanted to quantify the rate of change of ethane gas molecules in the adsorbed state with change in pore pressure, herein referred to as the ethane desorption rate. Having an experimental setup where pressure comes to equilibrium after the pressure pulse decay at a different pressure than the initial soak period pressure allowed calculation of the ethane desorption rate.

2.4. Ethane Desorption Rate Calculations. Ethane desorption rates were calculated using the pressure data collected during permeability measurements. The desorption rate is equivalent to the slope of the desorption isotherm at the pore pressure of the permeability measurement. Desorption rate is quantified because it represents how much liquid/semiliquid ethane saturation changes between successive ethane permeability measurements at different mean pore pressures. Because gas pressure is bled from the system when generating differential pressure across the sample, gas pressure in the upstream reservoir, downstream reservoir, and sample pore volume come to equilibrium at a lower pressure than the initial soak period equilibrium pressure. The permeameter is a closed system once the differential pressure is created, so gas 


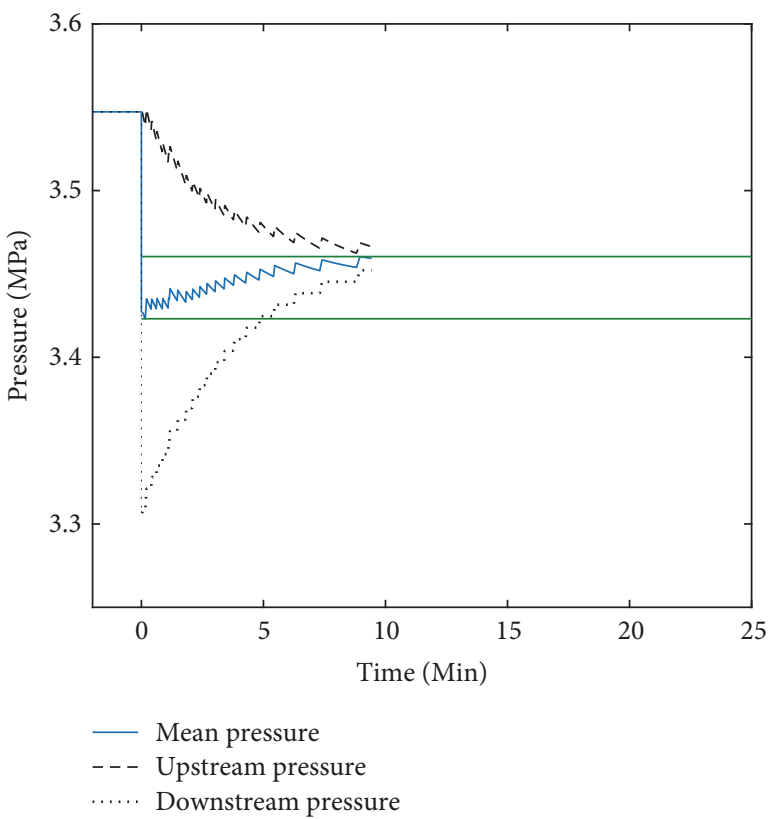

(a)

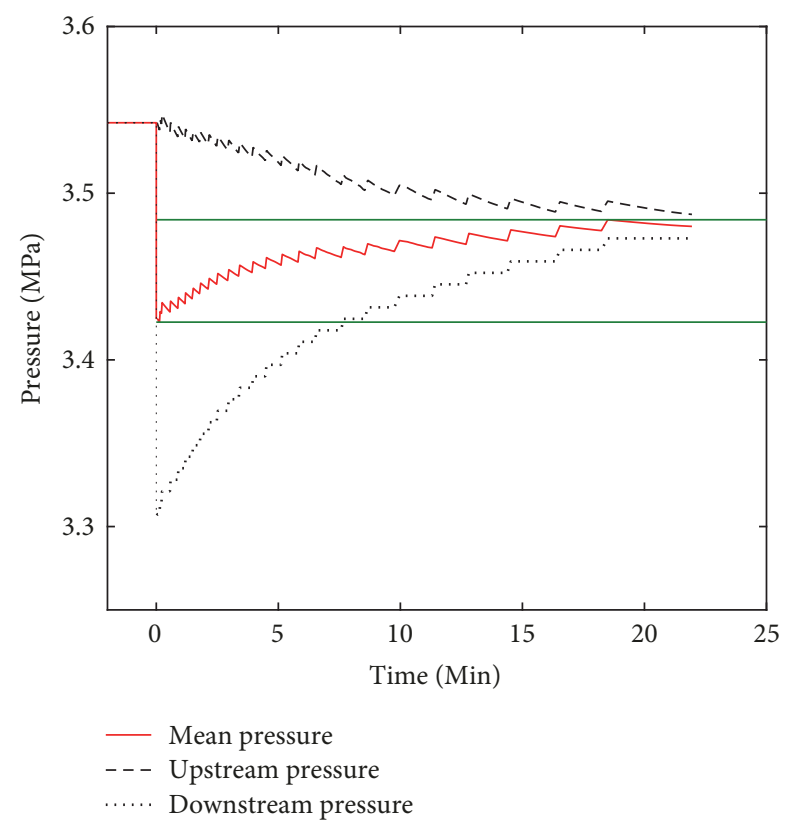

(b)

Figure 4: Comparison of helium (a) and ethane (b) pulse decay data for sample B5FD2A2. Mean pore pressure increases throughout the helium permeability measurement because the upstream reservoir of the permeameter is larger than the downstream reservoir, and gas was bled from the downstream reservoir to generate the differential pressure. Mean pore pressure increases by more in the ethane measurement than the helium measurement because liquid/semiliquid ethane desorbs to reach equilibrium at the final gas pressure, which is lower than the equilibrium gas pressure during the soak period (time $<0$ on graphs). Differential pressure in the ethane permeability measurement takes more than twice as long to decay than the helium differential pressure because adsorbed liquid/semiliquid ethane constricts flow paths resulting in lower ethane gas permeability. Green lines indicate the difference between minimum mean pressure and final equilibrium pressure.

molecules that desorb from the sample due to the drop in pore pressure result in higher post-decay equilibrium gas pressure than if no molecules were to desorb (Figure 4). Using the pressure data, the known reservoir volumes, and estimates of pore volume, Boyle's Law was used to calculate the amount of gas molecules desorbed per MPa drop in total system pressure at the mean pore pressure of each permeability measurement (the ethane desorption rate). Pore volumes were estimated from the dimensions of the samples and porosities determined using a combination of unconfined helium pycnometry and mercury immersion. For the ethane desorption rate calculations, compressibility factors were calculated using the Peng-Robinson equation of state [21].

2.5. Ethane Gas Slippage Estimates. Mean free path decreases with increasing gas pressure resulting in gas slippage being less significant and therefore lower apparent permeability [10]. When ethane is used as a probing gas, effective permeability to ethane gas varies with pore pressure not only due to gas slippage, but also due to changes in liquid/semiliquid ethane saturation resulting from adsorption and capillary condensation. In order to distinguish these two components of permeability variation, Klinkenberg's slippage factor for ethane was calculated by multiplying the slippage factor measured for helium by the ratio of ethane mean free path to helium mean free path at a given pressure and temperature. This ratio is equal to the kinetic diameter of helium $(0.26 \mathrm{~nm}$ [22]) squared over the kinetic diameter of ethane $(0.44 \mathrm{~nm}$
[23]) squared (see (3)). Expected ethane permeability variation due to gas slippage was then calculated using the lowest pressure ethane permeability measurement and the calculated ethane slippage factor.

\section{Results}

3.1. Helium Klinkenberg Plots. $K_{\infty}$ from extrapolation of Klinkenberg plots ranges from $3 \times 10^{-5}$ to $2 \times 10^{-2} \mathrm{mD}$ (Figure 5 ). $K_{\infty}$ of sample TEFB9 parallel to bedding decreases with increasing simple effective stress from $2 \times 10^{-2} \mathrm{mD}$ at $7 \mathrm{MPa}$ simple effective stress to $8 \times 10^{-4} \mathrm{mD}$ at $48 \mathrm{MPa}$ simple effective stress. $K_{\infty}$ of sample TEFB9 perpendicular to bedding at $7 \mathrm{MPa}$ simple effective stress is two orders of magnitude lower than to flow parallel to bedding at the same stress state.

Dominant pore diameter, $d$, ranges from $42 \mathrm{~nm}$ to $473 \mathrm{~nm}$ (Figure 6). Rocks with lower permeability have smaller pores (Figure 6). This however is only a general trend with a high degree of scatter. For example, samples MONT and TEF21 have the same dominant pore size but permeabilities that differ by an order of magnitude (yellow triangle and red star in Figure 6).

3.2. Ethane Permeability. Ethane permeability of all samples under all stress states and flow orientations decreases with increasing pore pressure (Figure 7). At mean pore 

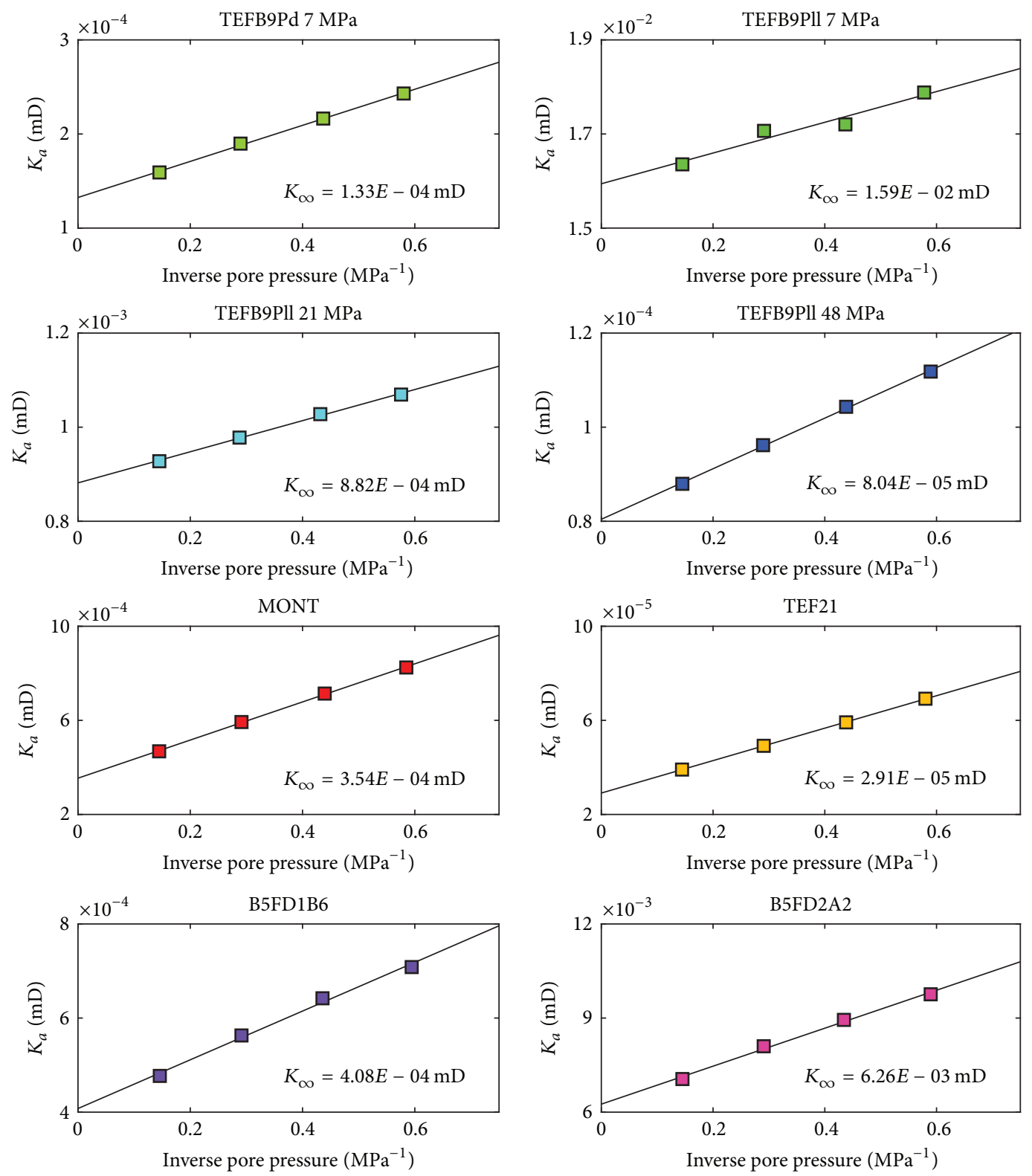

FIGURE 5: Klinkenberg plot for each sample generated using the helium permeability data.

pressures less than $2.3 \mathrm{MPa}$, the decreases in permeability closely match the predicted permeability decreases due to gas slippage (Figure 7). Ethane permeability deviates from what is predicted due to gas slippage (becoming lower) at higher pore pressures (Figure 7). The pore pressure where deviation takes place varies within the sample suite. The lowest pressure permeability deviation is sample MONT at $\sim 2.3 \mathrm{MPa}$ (Figure 7), whereas for other samples deviation does not occur until pressures are above $3 \mathrm{MPa}$.

At higher pore pressures, all samples have lower permeability than what is predicted due to gas slippage, but the magnitude of the difference between measured permeability and predicted permeability varies within the sample suite; at $3.45 \mathrm{MPa}$ mean pore pressure (the highest mean pore pressure measured), the difference between measured permeability and permeability predicted due to gas slippage ranges from 28 to 84 percent (Table 1, column 6).

3.3. Ethane Desorption Rates. Ethane desorption rates over the pressure range of the permeability measurements are only presented for the five highest permeability samples (Figure 8). Desorption rates for the three lowest permeability samples (TEF21, TEFB9Pd at $7 \mathrm{MPa}$ SES, and TEFB9Pll at $48 \mathrm{MPa}$ SES) are not presented because accurate calculations could not be made from the pressure data. Differential pressure was only allowed to partially decay for the low permeability measurements due to the excessive time required for full pressure decay (multiple days to weeks). Pressure data would 
TABLE 1: Experimental conditions and tabulated data for each sample.

\begin{tabular}{lccccc}
\hline Sample & Simple effective stress $(\mathrm{MPa})$ & $K_{\infty}(\mathrm{mD})$ & $b_{\text {helium }}$ & $b_{\text {ethane }}$ & \% permeability drop at 3.45 MPa \\
\hline TEFB9Pll & 7 & $1.59 E-02$ & 0.20 & 0.07 & 33 \\
TEFB9Pll & 21 & $8.82 E-04$ & 0.38 & 0.13 & 39 \\
TEFB9Pll & 48 & $8.04 E-05$ & 0.67 & 0.23 & 45 \\
TEFB9Pd & 7 & $1.33 E-04$ & 1.45 & 0.51 & 28 \\
MONT & 21 & $3.54 E-04$ & 2.29 & 0.80 & 84 \\
TEF21 & 21 & $2.91 E-05$ & 2.37 & 0.83 & 76 \\
B5FD1B6 & 7 & $4.08 E-04$ & 1.27 & 0.44 & 29 \\
B5FD2A2 & 21 & $6.26 E-03$ & 0.97 & 0.34 & 44 \\
\hline
\end{tabular}

* Percent difference between predicted permeability and measured ethane gas permeability at 3.45 MPa mean pore pressure.

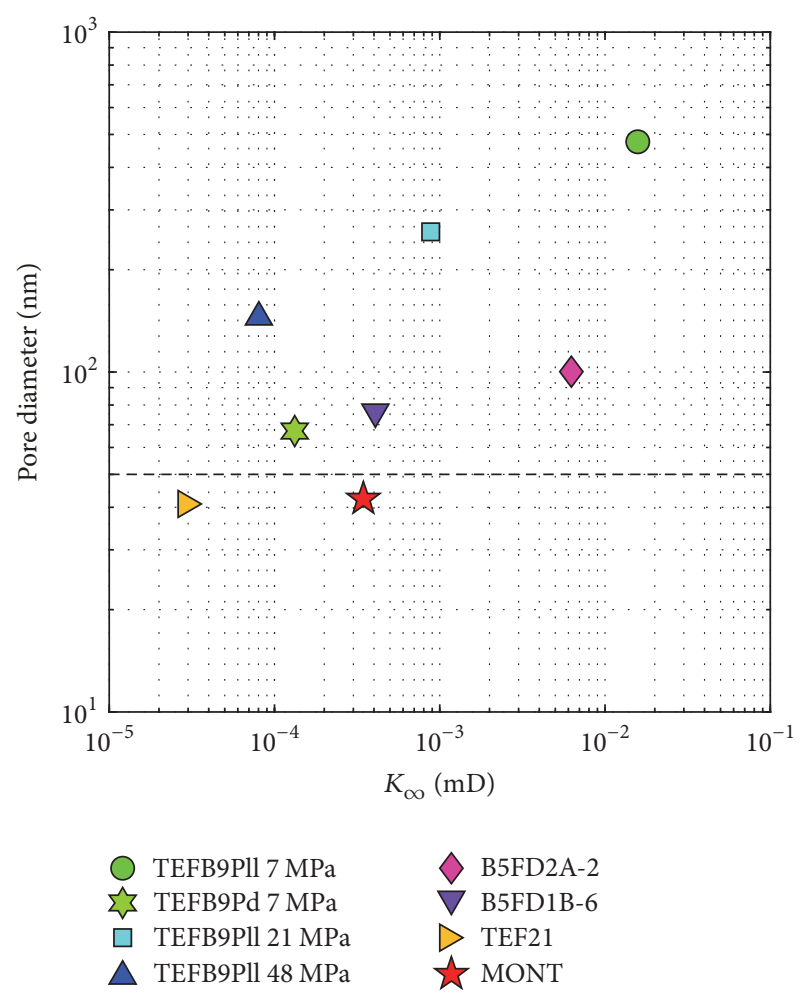

Figure 6: Dominant pore size calculated using (2) and the helium Klinkenberg plot data. Pores are generally smaller in samples with lower $K_{\infty}$, but with lots of variability around the trend. Dashed line delineates the macropore-mesopore boundary below which capillary condensation is expected at ethane gas pore pressures close to the saturated vapour pressure [6].

therefore have to be extrapolated to estimate the final equilibrium pressure after decay. Additionally, because pressure data series for the lowest permeability samples are collected over a longer time scale (days) than higher permeability samples (minutes to hours), small temperature fluctuations can significantly influence mean pore pressure (Figure 9). The data were collected in a temperature controlled environment, but at the time scale of days, temperature drifts on the order of a quarter of a degree Celsius take place (e.g., Figure 9(d)).

Sample TEFB9Pll at 7 and $21 \mathrm{MPa}$ simple effective stress and sample B5FD2A2 all show measurably elevated ethane desorption rates at high pore pressure (Figure 8). Samples MONT and B5FD1B6 do not show measurably elevated desorption rates at any mean pore pressure. Calculated desorption rates are slightly negative at some mean pore pressures for samples MONT and B5FD1B6.

\section{Discussion}

4.1. Desorption Rate Data Quality. Measured desorption rates are valuable data in this study because they represent by how much liquid/semiliquid ethane saturation is changing between successive permeability measurements, and the goal of the study is to make matrix permeability measurements at different fluid saturations. However, the apparatuses used to measure desorption rates in this study (pulse decay permeameters) are not optimized for measuring this rate. A discussion of the resulting data quality is therefore required.

The negative desorption rates calculated at some pore pressures for samples MONT and B5FD1B6 counterintuitively suggest desorption of ethane is occurring when pressure is increasing. These negative rates are not real but are an artifact resulting from the resolution limit of the experimental setup combined with temperature fluctuation (Figure 9). Because the upstream and downstream reservoirs of the permeameters used in this study were chosen to be much larger than the pore volumes of the samples (in order to minimize permeability measurement error due to adsorption), ethane desorbing during permeability measurements only resulted in small mean pore pressure increases $(0.06 \mathrm{MPa}$ at most). Small temperature fluctuations therefore result in significant absolute errors in measured desorption rates and large relative errors for small desorption rates. Because of the errors, it is possible that when the calculated desorption rates are near-zero, liquid/semiliquid ethane saturation could be increasing by small amounts between successive permeability measurements.

To illustrate how near-zero desorption rates that cannot be accurately quantified from the pulse decay pressure data could in fact represent small but significant changes in liquid/semiliquid ethane saturation, desorption rate data for sample TEFB9Pll at $7 \mathrm{MPa}$ simple effective stress is converted to a liquid/semiliquid ethane saturation curve (Figure 10). This sample is the highest permeability sample of the suite and therefore has the highest quality pressure data for calculating 

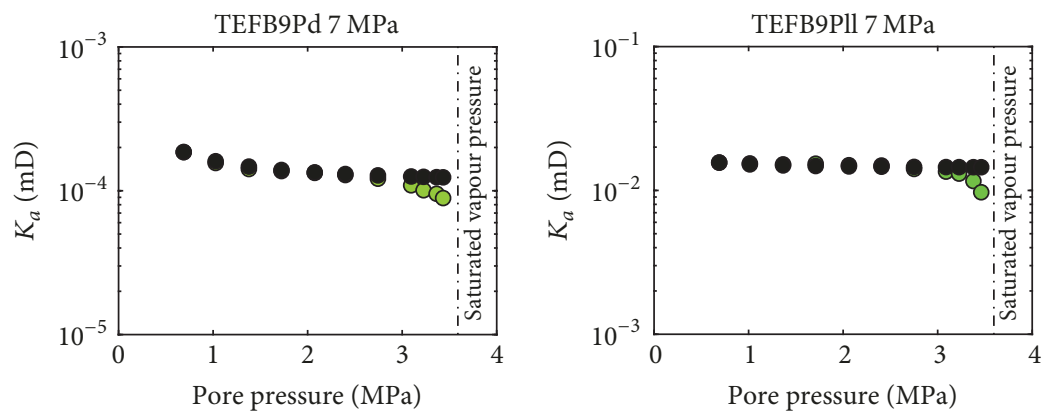

O Ethane

- Slip prediction

O Ethane

- Slip prediction
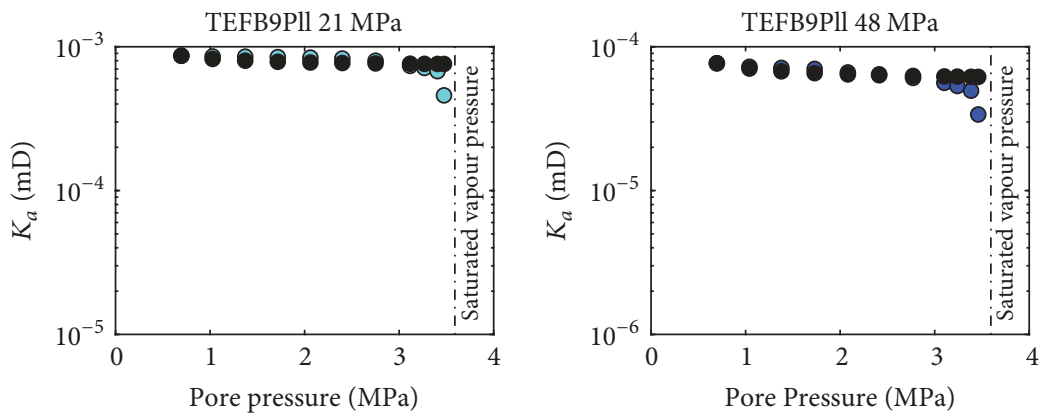

O Ethane

- Ethane

- Slip prediction

- Slip prediction
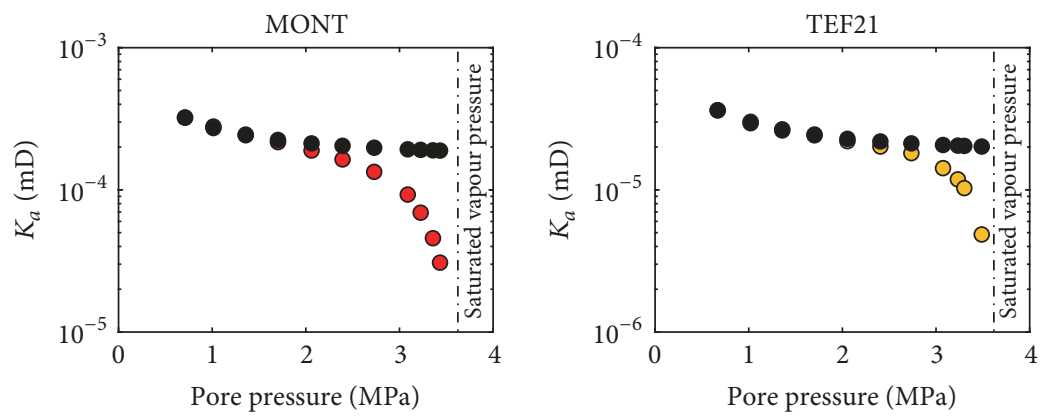

- Ethane

- Slip prediction

O Ethane

- Slip prediction
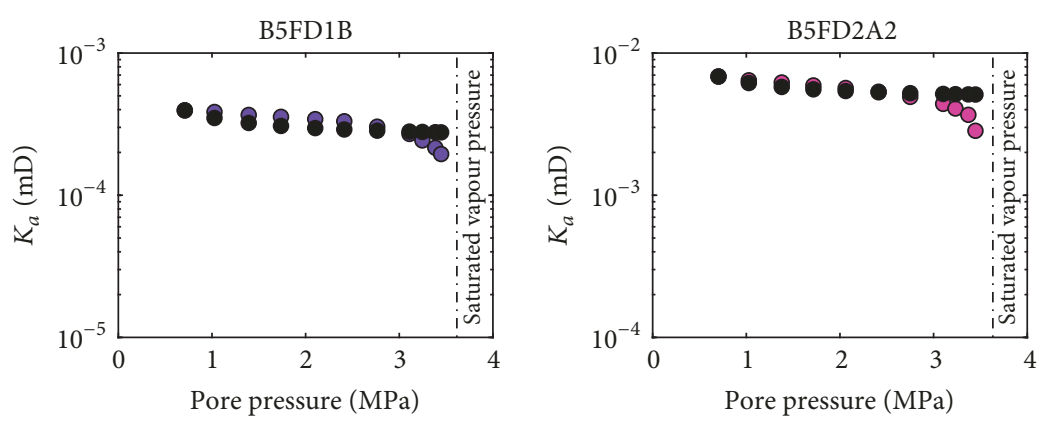

- Ethane

- Slip prediction

- Ethane

- Slip prediction

FIGURE 7: Ethane permeability measurements (coloured markers) and predicted permeability variation due to gas slippage (black markers) calculated using the ethane slippage factor, which was derived from the helium permeability data. 

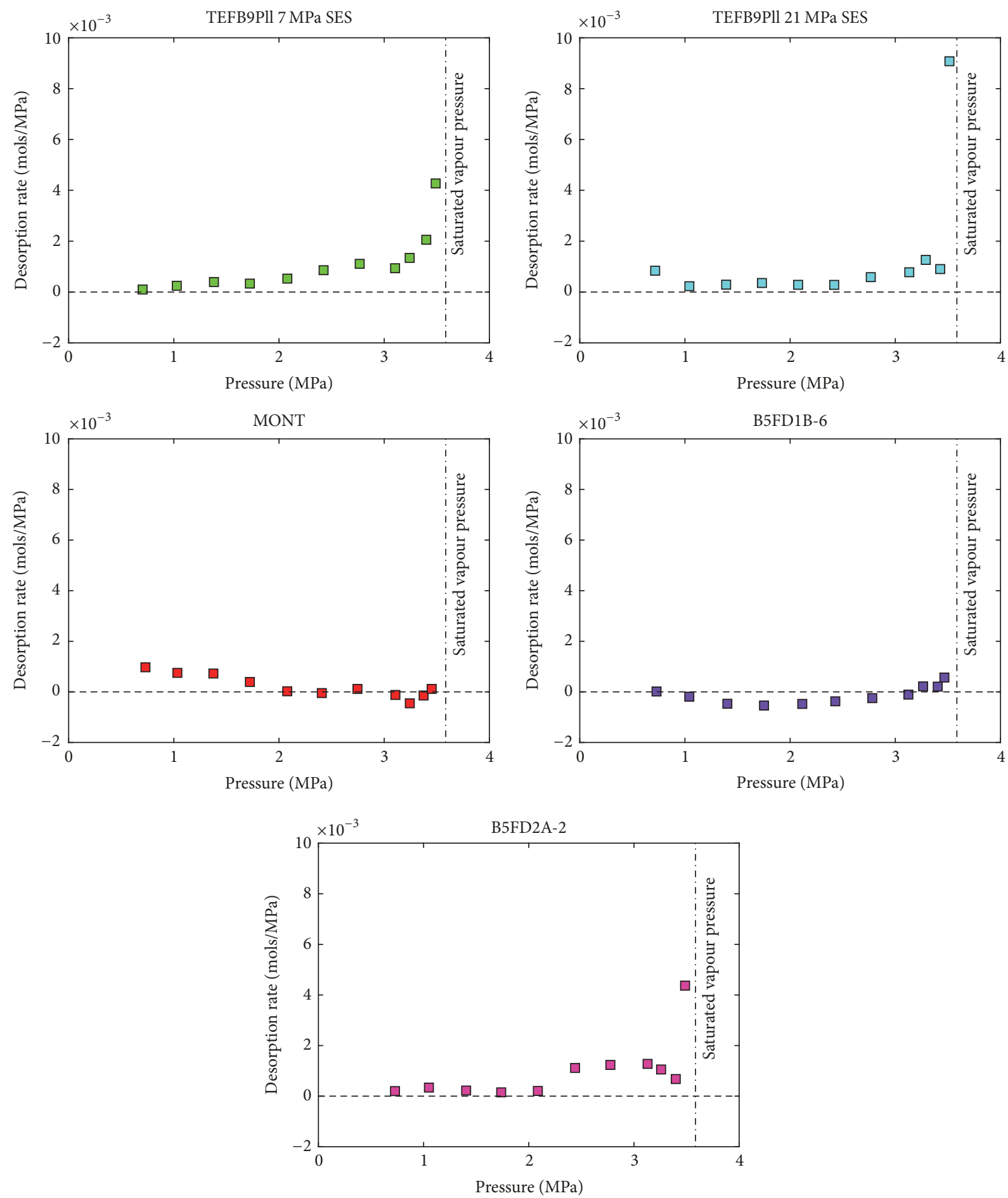

Figure 8: Ethane desorption rates calculated from the pulse decay pressure data. Desorption rate is elevated at high pressures for sample TEFB9Pll at 7 and $21 \mathrm{MPa}$ simple effective stress and sample B5FD2A2. Desorption rate is not elevated above resolution limit for samples MONT and B5FD1B6.

desorption rates (it was the least susceptible to temperature fluctuation). An adsorbed liquid/semiliquid fluid density of 11553 moles per $\mathrm{m}^{3}$, the density of liquid ethane at the ethane saturated vapour pressure at $18^{\circ} \mathrm{C}$ [19], is assumed for the calculations. Liquid/semiliquid ethane saturation in the sample increases by a small but not insignificant $~ 5 \%$ between
0.7 and 2.2 MPa mean pore pressure (Figure 10) even though desorption rate is only slightly above zero over this pressure range (Figure 8). Due to the resolution limit of the desorption rate measurements, sources of error (temperature fluctuation), and the assumed density, the ethane saturation curve in Figure 10 is a crude estimate and saturation curves for 


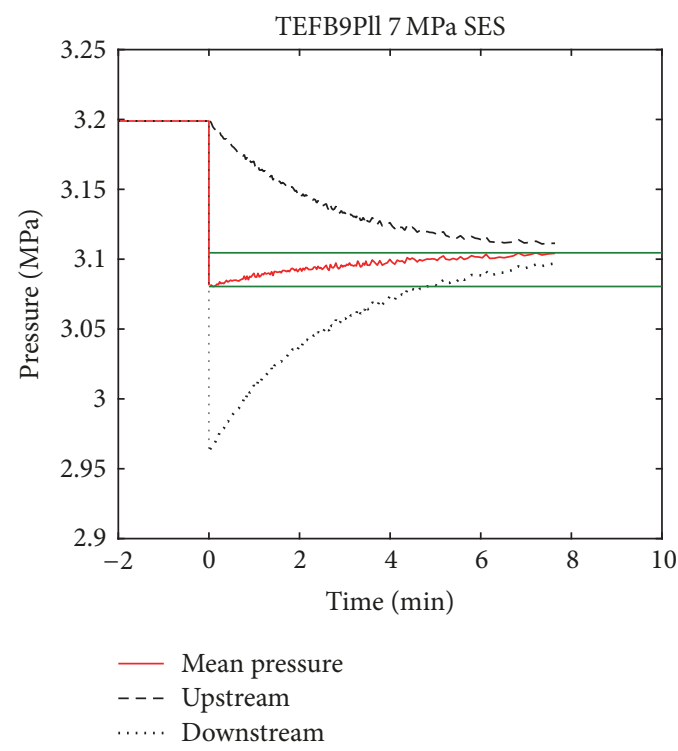

(a)

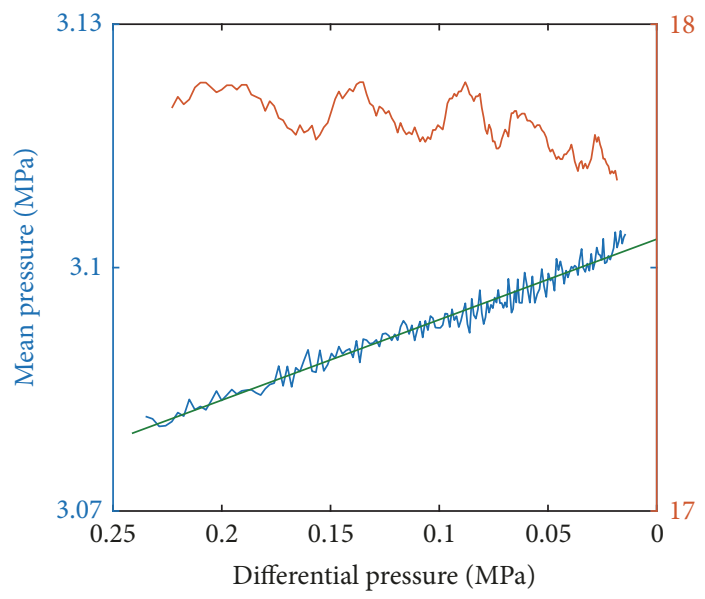

(c)

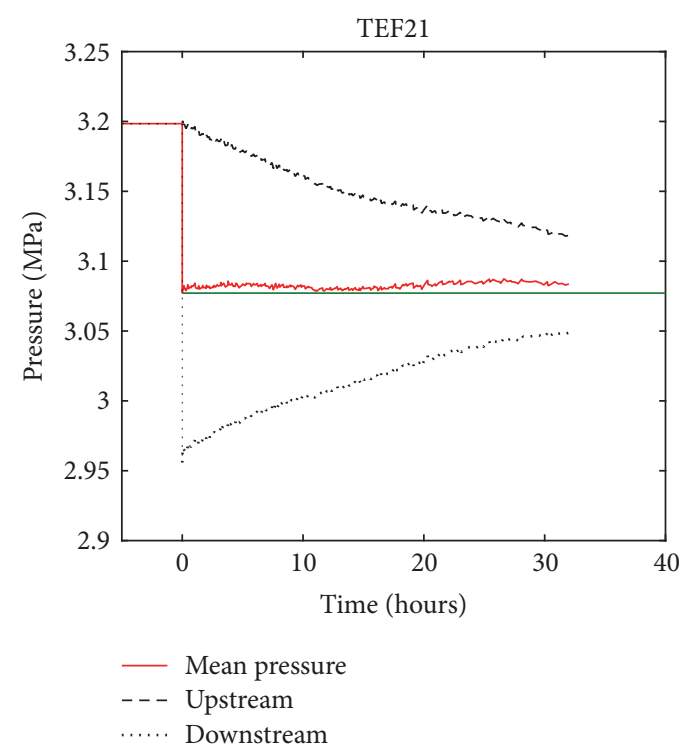

(b)

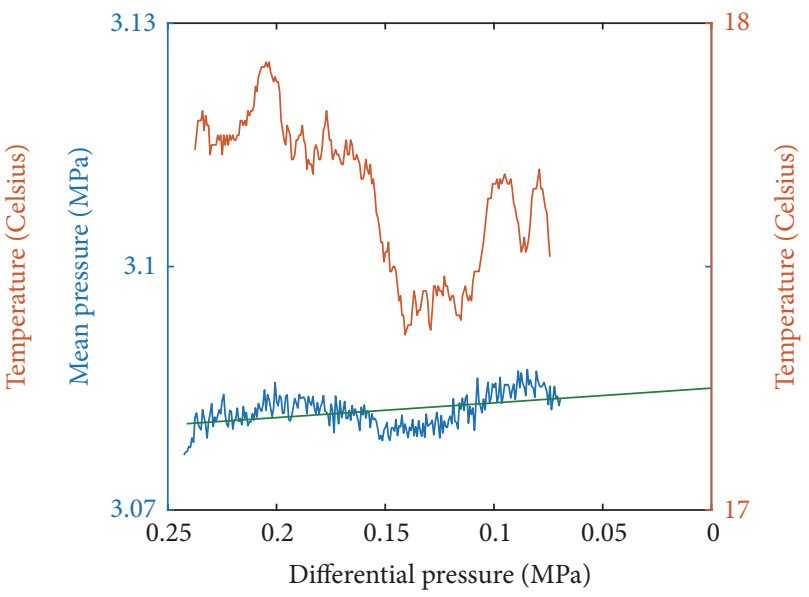

(d)

FIGURE 9: Examples of good quality ethane pulse decay pressure data for a high permeability sample from which accurate desorption rates could be calculated ((a) and (c)) and poor quality data for a low permeability sample from which accurate desorption rates could not be calculated ((b) and (d)). Temperature fluctuation over the duration of the measurement has a significant impact on mean pore pressure for the low permeability sample (d). Data collection for the low permeability sample was stopped at $\sim 0.07 \mathrm{MPa}$ differential pressure because of the excessive time required for full decay (b). Green lines in (a) and (b) indicate the difference between minimum mean pressure and final equilibrium pressure.

lesser quality data from lower permeability samples are not presented.

4.2. Ethane Permeability at Low Pore Pressures. At low pore pressures $(<2 \mathrm{MPa})$, the close match between apparent ethane permeability and permeability variation predicted due to gas slippage (Figure 7) indicates that adsorption of liquid/semiliquid ethane is not significantly impacting ethane gas permeability. If liquid/semiliquid ethane was blocking fluid flow, measured apparent permeability would be lower than predicted permeability. Ethane desorption rates for all samples with desorption data are near zero at pore pressures less than 2.2 $\mathrm{MPa}$ (Figure 8), indicating no changes in liquid/semiliquid ethane saturation between successive permeability measurements or changes so small they are not measurable with our experimental setup. No, or very small, liquid/semiliquid ethane saturation increases with increasing pore pressure explains the lack of deviation from permeability variation predicted due to gas slippage.

4.3. Ethane Permeability at High Pore Pressures. At high ethane pore pressures, ethane adsorption \pm capillary condensation results in constrictions \pm restrictions of fluid flow pathways and hence lower ethane gas permeability than is predicted due to gas slippage (Figure 7). Permeability decreases are substantial with up to an $84 \%$ difference 


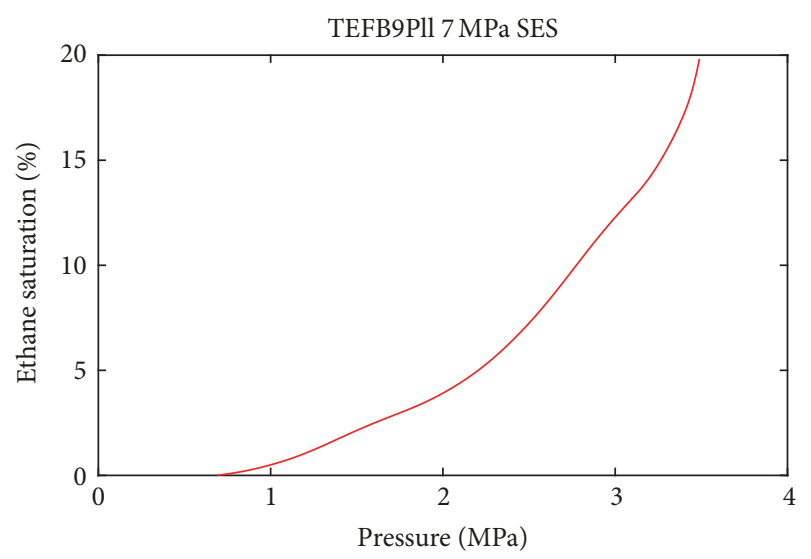

FIGURE 10: Liquid/semiliquid ethane saturation curve for sample TEFB9Pll at $7 \mathrm{MPa}$ simple effective stress.

between measured and predicted apparent ethane permeability (Table 1). The large permeability decreases indicate that permeability of fine-grained rocks with nanometer-scale pore systems can be very sensitive to change in fluid saturation.

Significant increases in liquid/semiliquid ethane saturation with increasing pore pressure are inferred from elevated desorption rates for three of the five samples with desorption data (Figure 8). These desorption rates however do not correlate well with the measured apparent permeability decreases; desorption rates are below measurement resolution over the entire pore pressure range of the ethane permeability measurements for sample MONT (Figure 8) even though that sample has the largest ethane gas permeability decrease relative to predicted permeability (84\%).

Difference between predicted ethane gas permeability and measured permeability has a weak negative correlation with $K_{\infty}$ (Figure 11(a)). This correlation is expected because lower permeability rocks generally have smaller pores, and the flow capacity of smaller flow conduits should be more sensitive to liquid/semiliquid ethane adsorbed to conduit (pore) walls. A better segregation of the data however is found when difference between predicted ethane gas permeability and measured permeability is plotted against $d$ (Figure 11(b)). The two samples with markedly larger permeability drops (75\% and $84 \%$ ) have dominant pore sizes in the mesopore range compared to all other samples with smaller permeability drops $(<45 \%)$ and dominant pore sizes in the macropore range. $d$ represents an average size of the smallest pore throats along those flow paths responsible for the bulk of the fluid flux through the rock. If $d$ is in the mesopore range, the main fluid flow conduits can be completely blocked due to capillary condensation at pore pressures near to the saturated vapour pressure [6]. Complete blockage of these conduits explains the very large permeability decreases for the samples with $d$ less than $50 \mathrm{~nm}$ (MONT and TEF21, Figures 6 and 7).

Schematic pore network models illustrate the impact of pore structure on the sensitivity of ethane gas permeability to pore pressure (Figure 12). The pore network models are modifications of the network models in Sakhaee-Pour and Bryant [24]. Sakhaee-Pour and Bryant showed that acyclic pore models could reproduce the nonplateau like trends of capillary pressure versus saturation that are common for gas shales. A key attribute of acyclic pore models is that narrower pore throats do not limit accessibility to the wider pore throats [24]. The pore network model depicted in Figures 12 (a) and 12(b) is for a sample with pores in the portion of the pore structure most responsible for limiting fluid flow in the macropore range. This pore network could be used to represent sample TEFB9Pll at $7 \mathrm{MPa}$ simple effective stress. Ethane gas permeability is not very sensitive to pore pressure in this sample (Figure 7), but significant quantities of ethane gas are adsorbed at high pore pressure (Figures 8 and 10). Such data indicate that the main flow conduits have minimum pore throat sizes in the macropore size range that are not completely blocked off at ethane pressures near the saturated vapour pressure (Figure 12(b)). The sample, however, can store significant quantities of ethane in the liquid/semiliquid state in submacropore scale pores whose throats do not limit accessibility to the macropores (Figure 12(b)).

In contrast to TEFB9Pll and the schematic pore network in Figures 12(a) and 12(b), the main flow conduits of the pore network model presented in Figures 12(c) and 12(d) are in the mesopore size range. The mesopores are completely blocked off due to capillary condensation at ethane pressures near the saturated vapour pressure (Figure 12(d)), resulting in ethane gas permeability that is very sensitive to pore pressure. This pore network model would explain the experimental observations of sample MONT; $d$ was $41 \mathrm{~nm}$ for MONT and permeability of this sample was most sensitive to pore pressure.

4.4. Stress Sensitivity of Ethane Permeability. Increasing stress narrows the pores and pore throats in sample TEFB9Pll resulting in decreasing $K_{\infty}$ (Figure 5). $d$ decreases from 473 to 259 to $145 \mathrm{~nm}$ at 7,21 , and $48 \mathrm{MPa}$ simple effective stress, respectively (Table 1 ). Concomitantly, the difference between predicted permeability and measured ethane gas permeability at $3.45 \mathrm{MPa}$ mean pore pressure increases from $33 \%$ to $39 \%$ to $45 \%$ with increasing stress (Table 1 ) because liquid/semiliquid ethane adsorbed to pore walls has a greater impact on the flow capacity of smaller flow conduits than larger flow conduits. Stress sensitivity of permeability could only be evaluated for sample TEFB9 for flow parallel to bedding because TEFB9Pll was the only plug in this study measured at multiple stress states.

4.5. Anisotropy of Ethane Permeability. Permeability of sample TEFB9 is highly anisotropic; at $7 \mathrm{MPa}$ simple effective stress $K_{\infty}$ to helium parallel to bedding is two orders of magnitude higher than to flow perpendicular to bedding. Calculated $d$ of subsample TEFB9Pd at $7 \mathrm{MPa}$ simple effective stress $(67 \mathrm{~nm})$ is seven times smaller than $d$ of sample TEFB9Pll at $7 \mathrm{MPa}$ simple effective stress (473 nm). The large difference in dominant pore size explains the permeability anisotropy. The large difference in pore size however does not explain why ethane permeability is less sensitive to pore pressure at high pore pressures for flow perpendicular to bedding than for flow parallel to bedding; permeability to ethane gas should be more sensitive to adsorption and capillary condensation when flow is in the direction with smaller 


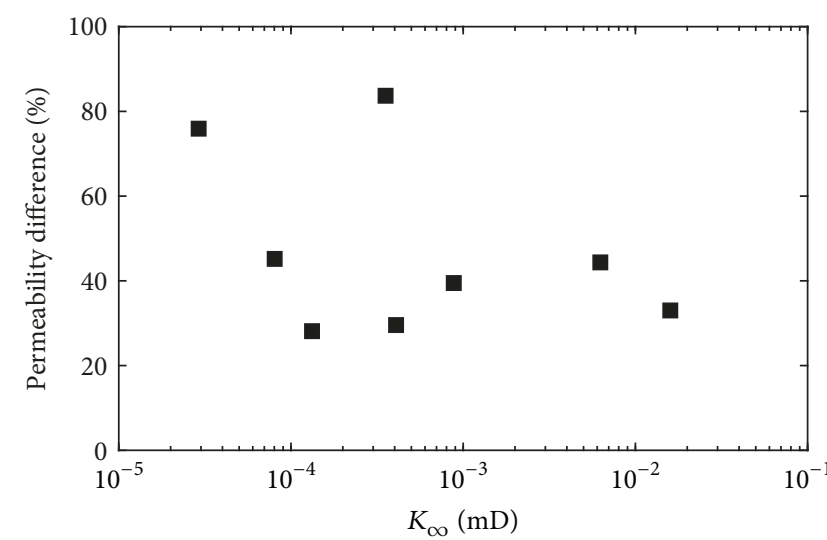

(a)

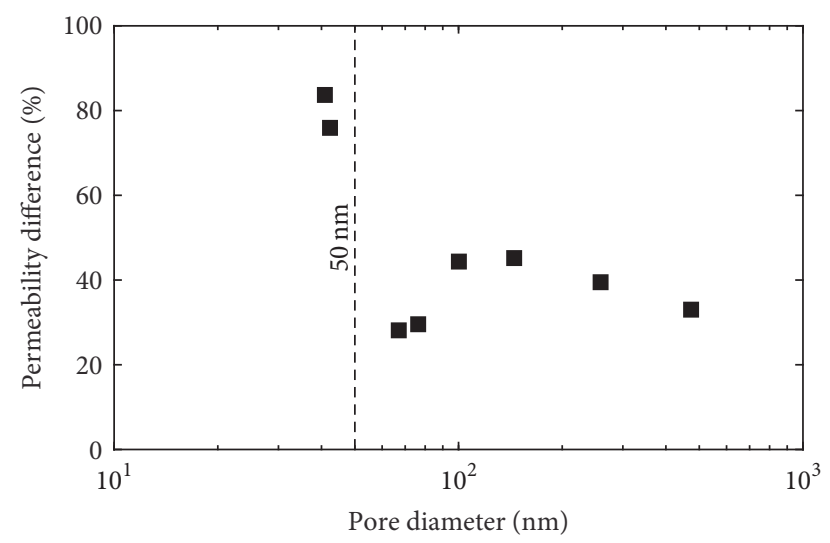

(b)

FIGURE 11: Correlation of difference between predicted ethane gas permeability and measured permeability at 3.45 MPa pore pressure ( $y$-axes) and $K_{\infty}(\mathrm{a})$ and $d(\mathrm{~b})$.

flow paths. The calculated dominant pore sizes, however, only represent an average size of the smallest pore throats along those flow paths responsible for the bulk of the fluid flux through the rock. In reality, the pore structure of sample TEFB9 is likely composed of a distribution of different sized pores. It is therefore possible that significant portions of fluid flow parallel to bedding take place along flow paths where the smallest pores are much smaller than the average, as well as in flow paths where the smallest pores are much larger than the average. For example, a continuous network of organic matter with connected, small pores (micro- to mesopores) could contribute significant flow parallel to bedding. This flow would be sensitive to adsorption and capillary condensation at high ethane gas pressures. Perpendicular to bedding, the organic matter might not be continuous and therefore would not contribute to flow. Perpendicular to bedding, the pores most responsible for limiting fluid flow could be on average smaller than parallel to bedding but have a narrower distribution of pore sizes that excludes the very small pores in the organic matter. Ethane permeability perpendicular to bedding could therefore be less sensitive than ethane permeability parallel to bedding to adsorption and capillary condensation at high ethane gas pressure.

4.6. Permeability Hysteresis. The measurements of effective permeability to ethane gas in this study were made over a range of increasing pore pressures. Permeability measurements over a range of decreasing pore pressures could also have been made to investigate the path dependence of permeability but were not made in this study due to time constraints. Capillary condensation is hysteretic [6]. In finegrained reservoir rocks with mesopores, it is therefore expected that liquid/semiliquid ethane saturation would be path dependent. Path dependent saturation should result in permeability hysteresis. Future studies should measure effective permeability to ethane gas over a range of both increasing and decreasing pore pressures to investigate permeability hysteresis. Valuable insights about pore structure could potentially be derived from analysis of permeability hysteresis loops.

\section{Conclusion}

Ethane gas permeability measurements on stressed samples can be used as a tool to explore multiphase flow phenomena in fine-grained sedimentary rocks at in situ reservoir stress conditions. Because pores in fine-grained sedimentary rocks are generally of submicrometer length scale, significant liquid/semiliquid ethane saturation exists due to adsorption and capillary condensation at ethane gas pressures near the saturated vapour pressure. The liquid/semiliquid ethane causes restrictions and blockages of flow pathways and therefore reductions to the flow capacity of fine-grained sedimentary rocks.

The sensitivity of ethane gas permeability to adsorption and capillary condensation at high pore pressures varies within the suite of stressed samples analyzed in this study. The variability is controlled by the size of the pores most responsible for limiting fluid flow, which can be determined using gas slippage measurements. Dominant pore size ranges from tens to hundreds of nanometers. Samples with dominant pore sizes in the mesopore range are far more sensitive to ethane gas pore pressure because capillary condensation causes complete blockage of the main flow conduits at pore pressures near the saturated vapour pressure.

The multiphase flow characteristics of sample TEFB9Pll vary with stress state; ethane permeability of sample TEFB9Pll is more sensitive to pore pressure at higher stress states. At higher stress states, the pores are smaller and therefore the presence of liquid/semiliquid ethane has a larger impact on flow capacity. The stress sensitivity of multiphase flow characteristics revealed here highlights the importance of measuring effective permeability at in situ reservoir stress conditions in order to obtain accurate reservoir simulation inputs. 
Low pressure

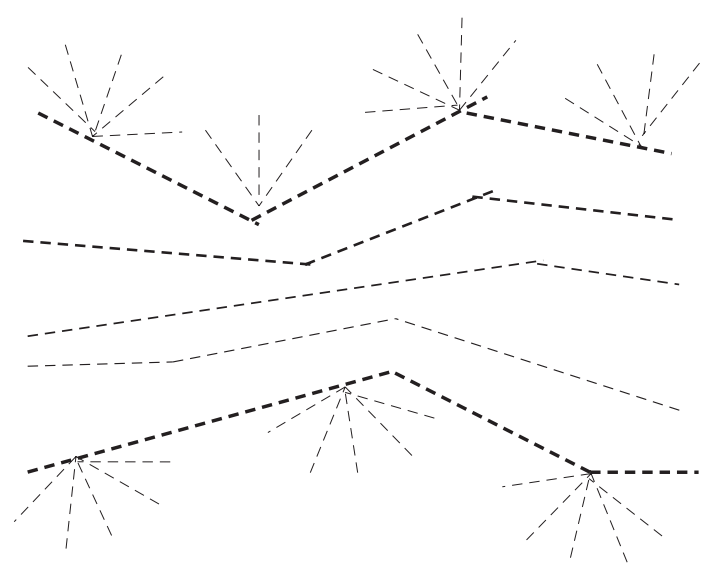

$--->150 \mathrm{~nm}$
$---75-150 \mathrm{~nm}$
$---50-75 \mathrm{~nm}$
- - $30-50 \mathrm{~nm}$

- - $<30 \mathrm{~nm}$

(a)

High pressure

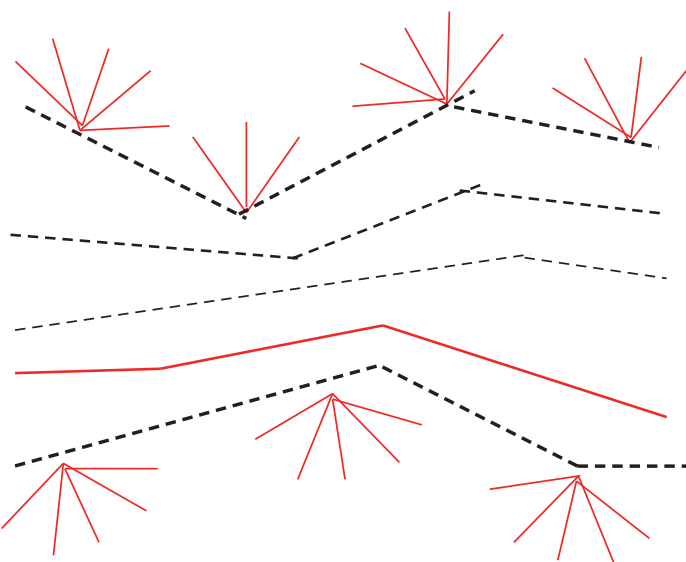

- - - > $150 \mathrm{~nm}$

- - $75-150 \mathrm{~nm}$

- - 50-75 nm

(b)

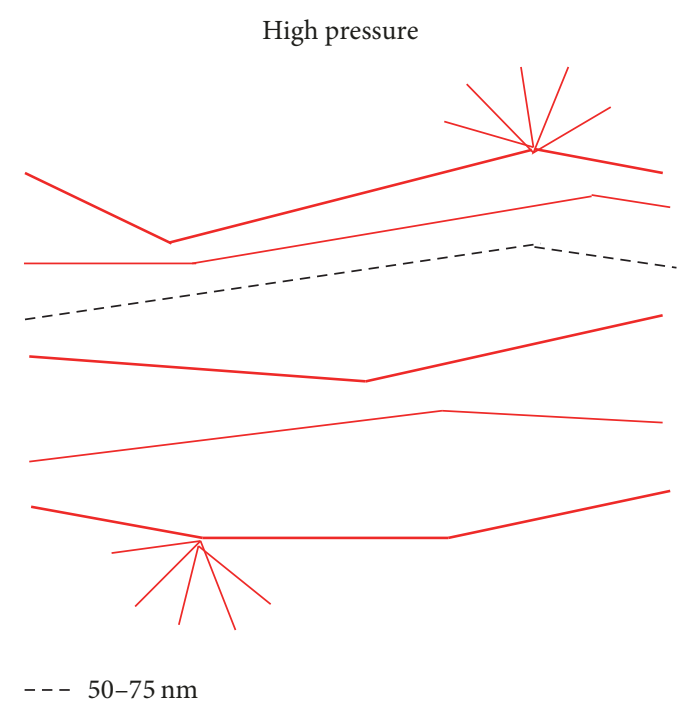

(d)

FIGURE 12: Acyclic pore network model for a pore structure where the pores most responsible for limiting fluid flow are in the macropore range ((a) and (b)) and mesopore range ((c) and (d)). Solid red lines indicate pores filled with liquid/semiliquid ethane. Ethane capillary condensation at high pore pressures completely blocks off the highest flow capacity flow paths in the mesoporous pore network (d) but has a limited impact on flow capacity in the macroporous pore network (b). Pore network models are modified from Sakhaee-Pour and Bryant, 2015.

\section{Conflicts of Interest}

The authors declare that there are no conflicts of interest regarding the publication of this paper.

\section{References}

[1] A. M. M. Bustin and R. M. Bustin, "Importance of rock properties on the producibility of gas shales," International Journal of Coal Geology, vol. 103, pp. 132-147, 2012.
[2] C. R. Clarkson, N. Solano, R. M. Bustin et al., "Pore structure characterization of North American shale gas reservoirs using USANS/SANS, gas adsorption, and mercury intrusion," Fuel, vol. 103, pp. 606-616, 2013.

[3] H. Aljamaan, M. Al Ismail, and A. R. Kovscek, "Experimental investigation and Grand Canonical Monte Carlo simulation of gas shale adsorption from the macro to the nano scale. Journal of Natural Gas Science and Engineering," Journal of Natural Gas Science and Engineering, vol. 48, pp. 119-137, 2016. 
[4] D. B. Bennion and S. Bachu, "Drainage and imbibition relative permeability relationships for supercritical $\mathrm{CO}_{2} /$ brine and $\mathrm{H}_{2} \mathrm{~S}$ /brine systems in intergranular sandstone, carbonate, shale, and anhydrite rocks," SPE Reservoir Evaluation and Engineering, vol. 11, no. 3, pp. 487-496, 2008.

[5] D. J. K. Ross and R. M. Bustin, "Impact of mass balance calculations on adsorption capacities in microporous shale gas reservoirs," Fuel, vol. 86, no. 17-18, pp. 2696-2706, 2007.

[6] S. J. Gregg, Adsorption, Surface Area, And Porosity, Academic Press, 1982.

[7] T. Tunstall, "Economic impact of the Eagle Ford Shale," in Petroleum Accounting and Financial Management Journal, vol. 33, no. 2, pp. 11-22, Denton, Tex, USA, 2014.

[8] C. Rivard, D. Lavoie, R. Lefebvre, S. Séjourné, C. Lamontagne, and M. Duchesne, "An overview of Canadian shale gas production and environmental concerns," International Journal of Coal Geology, vol. 126, pp. 64-76, 2014.

[9] W. F. Brace, J. B. Walsh, and W. T. Frangos, "Permeability of granite under high pressure," Journal of Geophysical Research: Atmospheres, vol. 73, no. 6, pp. 2225-2236, 1968.

[10] L. J. Klinkenberg, "The permeability of porous media to liquids and gases," in Drilling and Production Practice, American Petroleum Institute, New York, NY, USA, 1941.

[11] E. A. Letham, New insights into pore structure characterization and permeability measurement of fine-grained sedimentary reservoir rocks in the laboratory at reservoir stress states [doctoral, thesis], The University of British Columbia, Vancouver, Canada, 2018.

[12] H. Adzumi, "Studies on the flow of gaseous mixtures through capillaries. III. The flow of gaseous mixtures at medium pressures," Bulletin of the Chemical Society of Japan, vol. 12, no. 6, pp. 292-303, 1937.

[13] L. B. Loeb, The Kinetic Theory of Gases, Dover Publications, 2004.

[14] P. L. Randolph, D. J. Soeder, and P. Chowdiah, "Porosity and permeability of tight sands," in Proceedings of the SPE Unconventional Gas Recovery Symposium, Pittsburgh, Pa, USA, 1984.

[15] D. J. Soeder, "Porosity and permeability of eastern devonian gas shale," SPE Formation Evaluation, vol. 3, no. 1, pp. 116-124, 1988.

[16] S. C. Jones, "A technique for faster pulse-decay permeability measurements in tight rocks," SPE Formation Evaluation, vol. 12, no. 1, pp. 19-24, 1997.

[17] R. Feng, J. Liu, and S. Harpalani, "Optimized pressure pulsedecay method for laboratory estimation of gas permeability of sorptive reservoirs: Part 1-Background and numerical analysis," Fuel, vol. 191, pp. 555-564, 2017.

[18] X. Cui, A. M. M. Bustin, and R. M. Bustin, "Measurements of gas permeability and diffusivity of tight reservoir rocks: different approaches and their applications," Geofluids, vol. 9, no. 3, pp. 208-223, 2009.

[19] E. W. Lemmon, M. O. McLinden, and D. G. Friend, ““Thermophysical Properties of Fluid Systems" in NIST Chemistry WebBook, NIST Standard Reference Database Number 69," in National Institute of Standards and Technology, P. J. Linstrom and W. G. Mallard, Eds., Gaithersburg, Md, USA, 2017.

[20] R. Feng, S. Harpalani, and J. Liu, "Optimized pressure pulsedecay method for laboratory estimation of gas permeability of sorptive reservoirs: Part 2-experimental study," Fuel, vol. 191, pp. 565-573, 2017.

[21] D. Y. Peng and D. B. Robinson, "A new two-constant equation of state," Industrial \& Engineering Chemistry Fundamentals, vol. 15, no. 1, pp. 59-64, 1976.
[22] D. W. Breck, Zeolite Molecular Sieves-Structure, Chemistry, and Use, John Wiley \& Sons, 1974.

[23] S. Aguado, G. Bergeret, C. Daniel, and D. Farrusseng, "Absolute molecular sieve separation of ethylene/ethane mixtures with silver zeolite A," Journal of the American Chemical Society, vol. 134, no. 36, pp. 14635-14637, 2012.

[24] A. Sakhaee-Pour and S. L. Bryant, "Pore structure of shale," Fuel, vol. 143, pp. 467-475, 2015, https://doi.org/10.1016/j.fuel.2014 .11 .053 . 

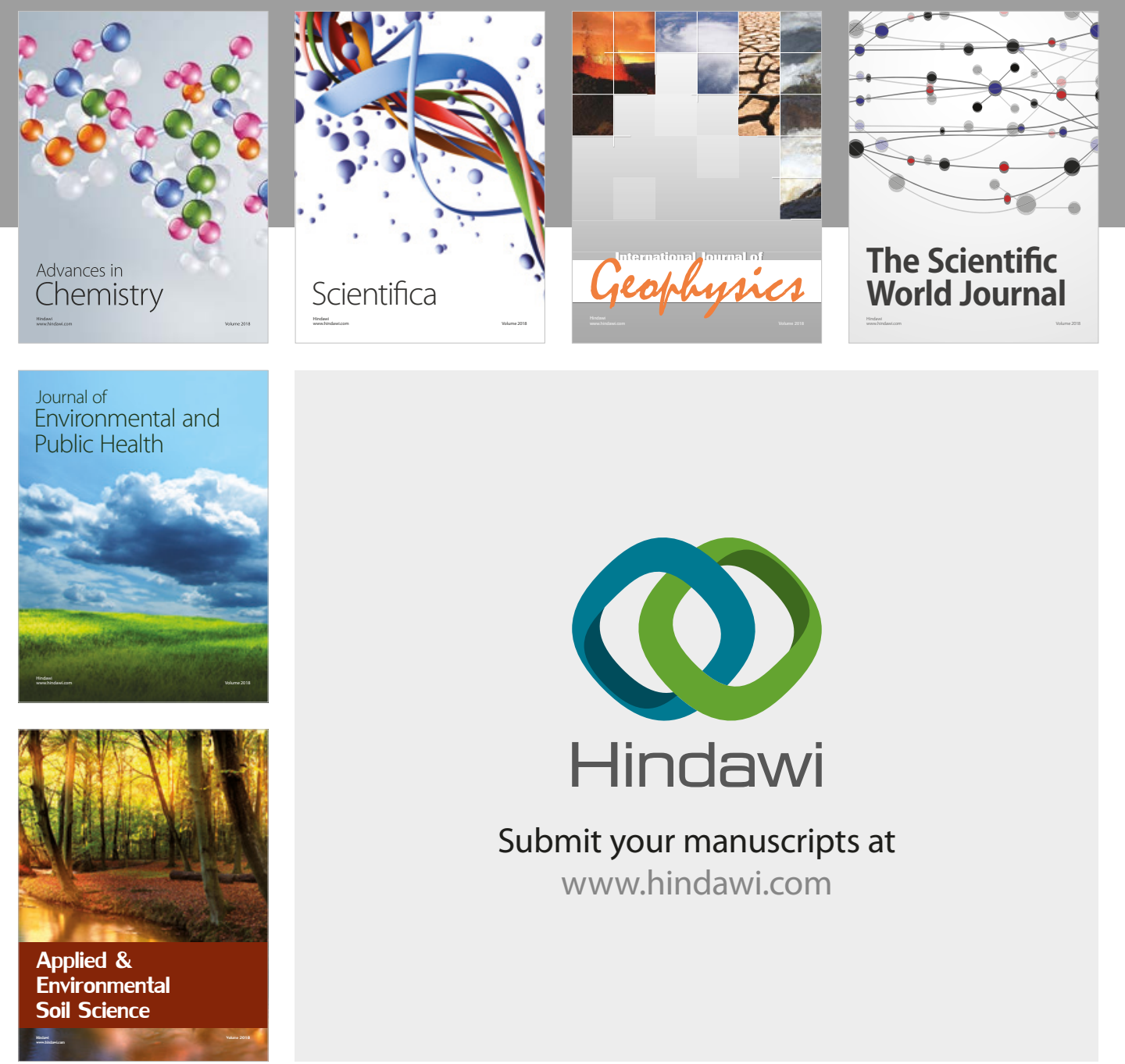

The Scientific

\section{World Journal}
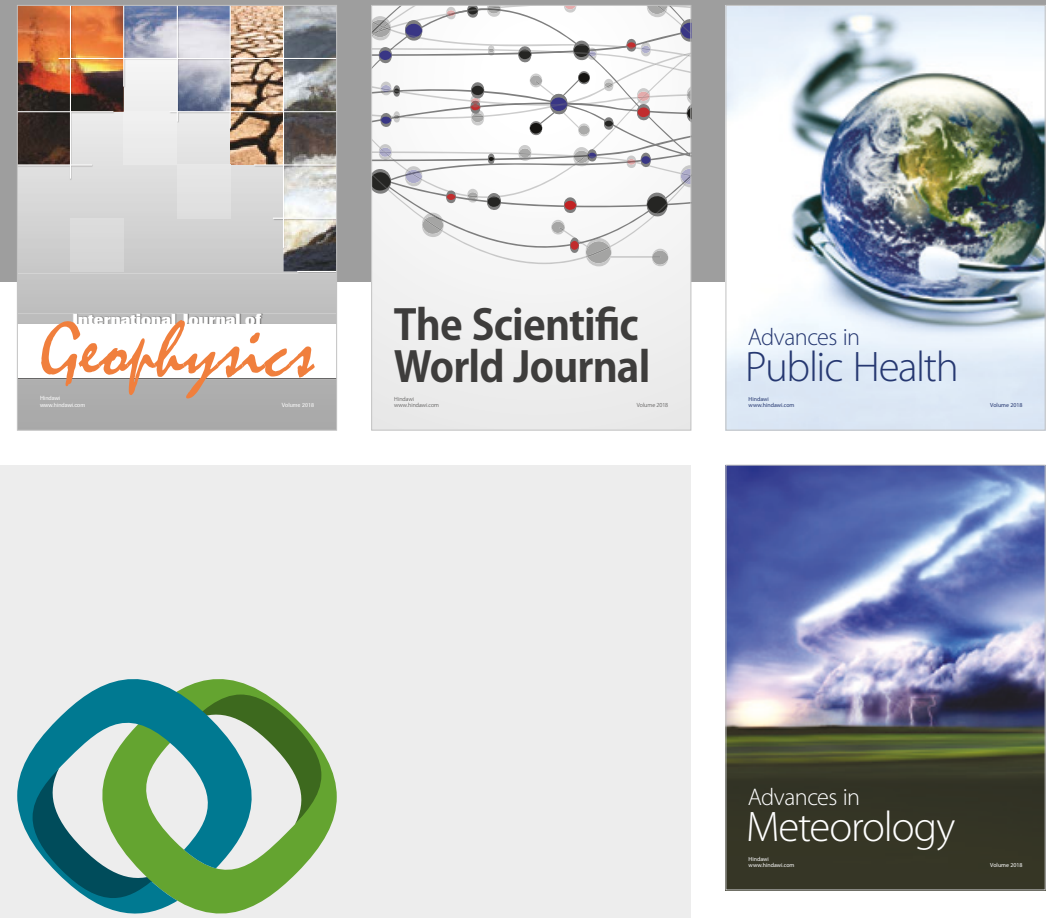

Advan

Public Health

\section{Hindawi}

Submit your manuscripts at

www.hindawi.com
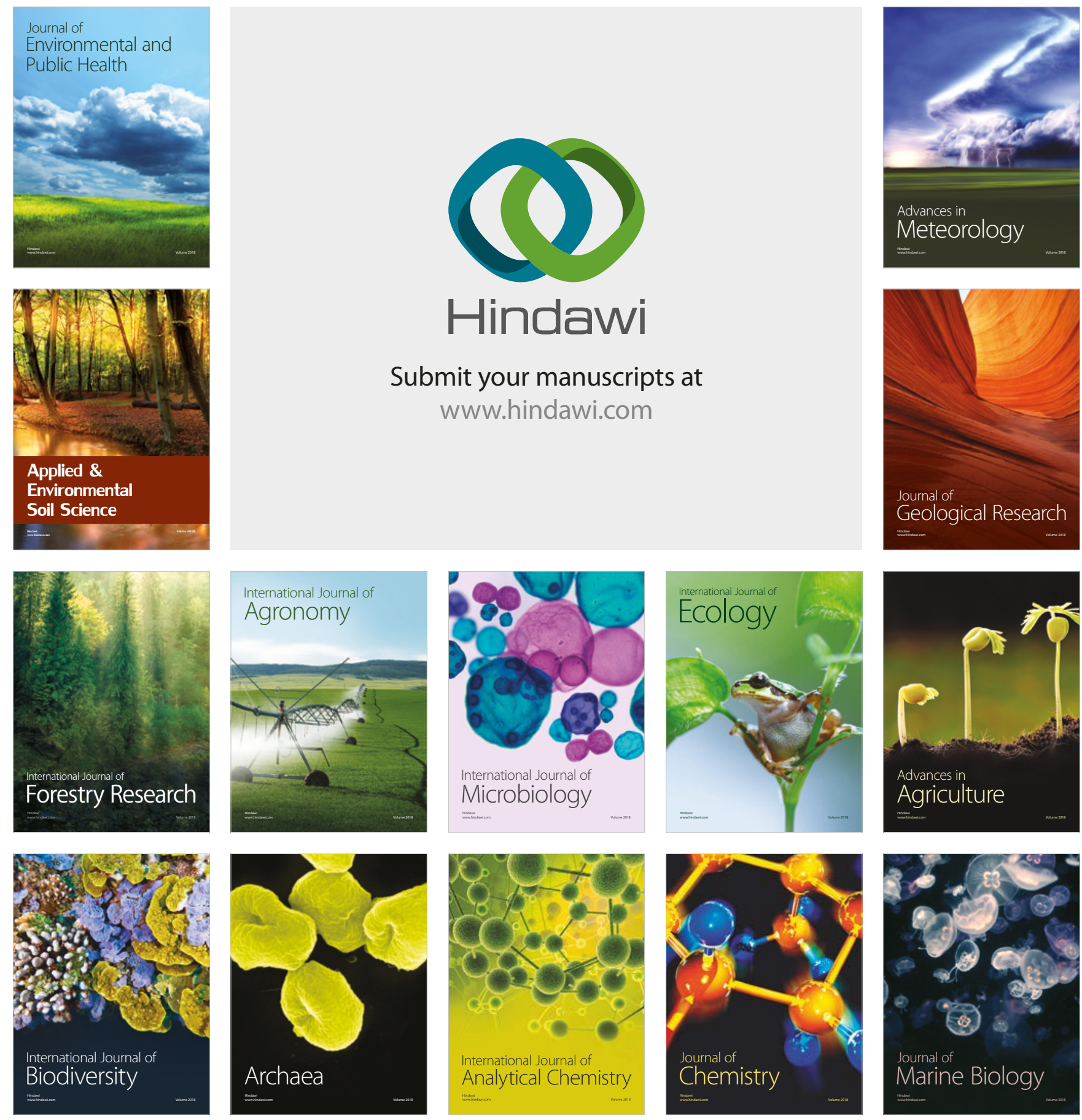